\title{
Residues of Organochlorine Compounds in Human Breast Milk Collected from Beijing, People's Republic of China
}

\author{
Z. Yao, ${ }^{1,3}$ Y. Zhang, ${ }^{2}$ G. Jiang ${ }^{1}$ \\ 1 Research Center for Eco-Environmental Sciences, Chinese Academy of Sciences, \\ Post Office Box 2871, Beijing, 100085, People's Republic of China \\ 2 Beijing Wangjing Hospital, Chinese Academy of Traditional Chinese Medicine, \\ Beijing, 100102, People's Republic of China \\ 3 National Marine Environmental Monitoring Center, State Oceanic Administration, \\ Dalian, 116023, People's Republic of China
}

Received: 22 January 2004/Accepted: 29 September 2004

Organochlorine pesticides were used in the agricultural production and for the control of parasites and pests for nearly seventy years. Although the beneficial effects of pesticides on the growth food supply are well recognized, the adverse effects of organochlorine pesticides and their metabolites have also been considered by many countries and organizations. Most of counties have strictly banned or restricted their production, usage and disposal since 1970s ( $\mathrm{Li}, 1999)$. But, several compounds remain detectable in many environmental matrixes around the whole world. Because these compounds are hardly degraded and lipid-soluble, they tend to bioaccumulate and biomagnify through the food chain and store in tissues or lipid rich organs such as adipose tissue and liver.

Organochlorine compounds (OCs) may enter human body as contaminants of dietary animal products. They store in adipose tissue, serum, or breast milk at similar levels on a fat weight basis and persist for a relatively long period (typically 5-10 years based on their half-lives). Monitoring of organochlorine pesticides in human milk is very important because infants do not have a fully developed detoxification mechanism and their immune systems and other organs are immature. On the other hand, during lactation process, organochlorine compounds in the body of the mother are mobilized and excreted with the milk. In fact, several studies (Jensen, 1983; Ejobi et al., 1996) have shown that milk secretion is the most important means of excretion of OCs in women. In China, the production and usage of technical HCHs and DDTs were banned in 1983; however, they had been found in all environmental matrixes, such as land, water, and air (Iwata et al., 1993), as a result of past production and subsequent distribution from polluted sites. In this study we report on the levels of organochlorine pollutants in human milk samples collected in Beijing (China) during 2000-2001. Levels of the residues of these compounds have been compared with data from other countries. Estimated daily intakes were calculated for the breast-fed infants and compared with the limits in human milk recommended by World Health Organization (WHO).

\section{MATERIALS AND METHODS}

Human milk samples were collected from lactating mothers who resided in Beijing, China. Each donor volunteered $\sim 50 \mathrm{~mL}$ of her breast milk by manual 
expression. Samples were collected into glass containers that had been thoroughly cleaned and rinsed in acetone and then carefully dried. Basic information of mothers, such as ages, occupation, possible pesticides exposure, dietary habits, long-term resident region, birth weights of the children were by questionnaire. Milk samples were frozen in a refrigerator at $-20{ }^{\circ} \mathrm{C}$ until analysis. The mixed OCPs standard solution was purchased from ChemService Inc. (West Chester, USA), including $\alpha-, \beta-, \gamma$ - hexachlorocyclohexane (HCH), heptachlor, heptachlor epoxide, dieldrin, endrin, o, $\mathbf{p}^{\prime}$-DDE, p, $\mathbf{p}^{\prime}$-DDE, $p, p^{\prime}$-DDD, and $p, p^{\prime}$-DDT. The storage solution was $20 \mathrm{ppm}$ in $n$-hexane and stored in the brown bottle in the refrigerator. 25\% Ammonia solution, Ethanol, ether, petroleum ester, n-hexane, and acetone used were of analytical-grade (Beijing Chemical Reagent Factory, China).

The frozen milk samples were placed in a water bath $\left(40^{\circ} \mathrm{C}\right)$ until thermal equilibrium was reached (approximately $30 \mathrm{~min}$ ). The whole milk sample was homogenized, and then fat content was determined using Rose-Getllieh Method. In brief, $2 \mathrm{~mL} 25 \%$ ammonia solution was added into $10 \mathrm{~g}$ milk sample, then $10 \mathrm{~mL}$ ethanol. After that, $25 \mathrm{~mL}$ diethylether was added and vortexed for $5 \mathrm{~min}$ to release the heat, then $25 \mathrm{~mL}$ petroleum ether was added. The tube was shaken for $10 \mathrm{~min}$. After phase separation, the upper organic phase was transferred to a conical flask, and the aqueous phase was extracted for the second time. The organic phases were combined and evaporated to dryness for the gravimetric determination of milk fat content. The fat was re-dissolved by $20 \mathrm{~mL} n$-hexane and acetone $(1: 1, v / v)$ mixture, and then the sample tube was placed in an ultrasonic bath for $20 \mathrm{~min}$. The tubes were centrifuged at $2000 \mathrm{rpm}$ for $10 \mathrm{~min}$ at room temperature. The lower aqueous phase was re-extracted by the same procedure and combined organic phases. The organic phases were evaporated to about $2 \mathrm{~mL}$ through rotary evaporator. The extract was added to a pre-filled glass column contained $5 \mathrm{~g}$ Florisil with a little sodium sulfate on the top. The column was eluted with $25 \mathrm{~mL}$ mixed $n$-hexane and petroleum ether $(80: 20, \mathrm{v} / \mathrm{v})$. The elute was concentrated and adjusted to $1 \mathrm{~mL}$ by $n$-hexane. Aldrin was added as internal standard before analysis.

$1 \mu \mathrm{L}$ of aliquot of the extracted organochlorine compounds was injected into a Hewlett-Packard 6890A gas chromatograph (GC) equipped with a ${ }^{63} \mathrm{Ni}$ micro-cell electron capture detector ( $\mu$-ECD) (Agilent, USA). A HP-1 fused-silica column $(30 \mathrm{~m} \times 0.25 \mathrm{~mm}$ I.D.) with $100 \%$ dimethylsiloxane (film thickness $0.25 \mu \mathrm{m}$ ) was used. The injector temperature was kept at $230^{\circ} \mathrm{C}$, and the detector temperature was maintained at $250{ }^{\circ} \mathrm{C}$. The column oven temperature was programmed as follows: initial temperature of $60^{\circ} \mathrm{C}$ for $1 \mathrm{~min}$, then rising to $150^{\circ} \mathrm{C}$ at a rate of $20^{\circ} \mathrm{C} / \mathrm{min}$ for $1 \mathrm{~min}$, and then to a final temperature of $270^{\circ} \mathrm{C}\left(10^{\circ} \mathrm{C} / \mathrm{min}\right)$. High purity nitrogen was used as carrier gas $(1.0 \mathrm{~mL} / \mathrm{min})$ and make-up gas $(40 \mathrm{~mL} / \mathrm{min})$.

\section{RESULTS AND DISCUSSION}


Characteristics of the donors in our study are summarized in Table1. Because of the family planning policy of Chinese government, most of the mothers were feeding their first child. The age of the mothers ranged from 23 to 34 years (mean age: 28.2 years). Eight donors (18\% of the total) were living in the rural region of Beijing city or came from countryside of other provinces in the recent years. Only one donor had contacted with pesticides directly for agricultural purpose. The lipophilic nature of organochlorine compounds enables them tend to exist in the fat of the milk, and the fat content of human milk vary continuously during lactation, depending on the economic and nutritional status (Jensen, 1983; Czaja et al., 2001), the fat contents in this research ranged from $1.13 \%$ to $8.22 \%$, with mean value $4.08 \%$.

Table 1. Summary of the basic information on our study.

\begin{tabular}{ll}
\hline Sample period & $2000 / 12 / 27-2001 / 07 / 31$ \\
\hline Total sample number & 45 \\
$\quad$ Urban residues & 37 \\
$\quad$ Rural residues & 8 \\
Lactation period (day) & $3-161$ \\
Age of the mother (year) & $23-34$ \\
$\quad$ Average & 28.3 \\
Fat content (\%) & $1.13-8.22 \%$ \\
Average & $4.08 \%$ \\
Status of the baby & \\
Sex & Male $25 ;$ Female 20 \\
Weight & $2.26-4.50 \mathrm{~kg}$ \\
Average weight & $3.56 \mathrm{~kg}$ \\
\hline
\end{tabular}

We performed the quantitative determinations of organochlorine compounds by internal standard procedure. The aldrin was used as internal standard. Recoveries of spiked cow's milk of different organochlorine compounds ranged from $80 \%$ to $95 \%$. The limits of detection (LODs) of OCPs were described as 3 of signal-to-noise ratio $(\mathrm{S} / \mathrm{N})$. The LODs of the method ranged from $0.1 \mathrm{ng} / \mathrm{g}$ whole milk for $p, p^{\prime}$-DDE to $1.0 \mathrm{ng} / \mathrm{g}$ whole milk for $\mathrm{p}, \mathrm{p}^{\prime}$-DDT. The mean value, range, and frequency of occurrence of organochlorine compounds in human milk are shown in Table 2 , both in whole milk and in fat weight. The major organochlorine compounds found in human milk are $\alpha-\mathrm{HCH}$ and p,p'-DDT, which were detected in about $35 \%$ of samples, but some pesticides $(\gamma-\mathrm{HCH}$ and p, $\mathbf{p}^{\prime}$-DDD) showed only in about $\mathbf{2 - 4 \%}$ of the samples. Others (i.e. dieldrin, endrin, heptachlor and heptachlor epoxide) were not detected in all of the samples. $\alpha-\mathrm{HCH}$ was found in $38.6 \%$ of the samples and $\beta-\mathrm{HCH}$ in $22.7 \%$, with a mean concentration of $63.9 \mathrm{ng} / \mathrm{g}$ fat weight (range not detected to $303.7 \mathrm{ng} / \mathrm{g}$ ) and $49.5 \mathrm{ng} / \mathrm{g}$ fat weight (range not detected to $259.1 \mathrm{ng} / \mathrm{g}$ ) respectively. The $\gamma$-isomer, which is the most toxic $\mathrm{HCH}$, was found in only $4.4 \%$ of the samples with a mean concentration of $55.6 \mathrm{ng} / \mathrm{g}$ fat weight (range not detected to $86.9 \mathrm{ng} / \mathrm{g}$ ). The highest mean concentrations of pesticides found in our study was p, $\mathbf{p}^{\prime}$-DDE, which maximum value reached $1333.9 \mathrm{ng} / \mathrm{g}$ fat weight, with a mean of $604 \mathrm{ng} / \mathrm{g}$ fat weight; meanwhile their original form, p, $\mathrm{p}^{\prime}$-DDT, varied from not detected to $188.8 \mathrm{ng} / \mathrm{g}$ fat weight, with a mean of $83.5 \mathrm{ng} / \mathrm{g}$. 
The total global HCH usage between 1948 and 1997 has been estimated to be approximately 10 million tons $(\mathrm{Li}, 1999)$. In general, technical HCHs contains the isomers in the following percentages: $\alpha: 55-80 \%, \beta: 5-14 \% ; \gamma: 8-15 \%, \delta$ : $2-16 \%$. As previous experimental test data showed, $\beta-\mathrm{HCH}$ is a more persistent contaminant (Hemandez et al., 1993). In our research, the $\beta-\mathrm{HCH}$ contains $37 \%$ of total $\mathrm{HCHs}$, which was higher than its percentage in technical HCHs. Because lindane (which contains more than $90 \%$ of $\gamma-\mathrm{HCH}$ ) was not used in large scales in China, the results are reasonable. By comparison with published data from other countries, total HCH residue levels in this study are lower than developing countries, such as India, Jordan, Turkey and Uganda, but higher than most of industrialized countries.

Table 2. Residues of organochlorine compounds in human milk in Beijing.

\begin{tabular}{llllllll}
\hline & \multicolumn{3}{c}{ ng/g (whole milk) } & \multicolumn{3}{c}{ ng/g (milk fat) } & \multirow{2}{*}{ Frequency (\%) } \\
\cline { 2 - 7 } & Max & Min & Mean* & Max & Min & Mean* & \\
\hline$\alpha-H C H$ & 5.5 & 0.2 & 2.2 & 303.7 & 4.4 & 63.9 & 38.6 \\
$\beta-H C H$ & 12.6 & 0.1 & 1.9 & 259.1 & 2.1 & 49.5 & 22.7 \\
$\gamma$-HCH & 1.4 & 0.6 & 1.0 & 86.9 & 24.2 & 55.6 & 4.5 \\
Total HCHs & & & 5.1 & & & 169 & \\
o,p'-DDE & 7.7 & 0.3 & 2.2 & 258.3 & 9.4 & 77.5 & 11.4 \\
p,p'-DDE & 92.8 & 0.7 & 19.8 & 1333.9 & 29.8 & 422.3 & 20.4 \\
p,p'-DDD & 9.5 & 9.5 & 9.5 & 135.8 & 135.8 & 135.8 & 2.2 \\
p,p'-DDT & 6.0 & 0.5 & 3.1 & 188.8 & 18.7 & 83.5 & 34.1 \\
Total DDTs & & & 34.6 & & & 719.1 & \\
\hline
\end{tabular}

* mean value is calculated by positive samples.

Many surveys have shown that the DDT contamination in human milk have been decreased significantly during last two decades. For example, during 1972-1992, the DDT and DDE residues in Swedish human milk decreased from 690 and $2500 \mathrm{ng} / \mathrm{g}$ to 22 and $227 \mathrm{ng} / \mathrm{g}$ fat, respectively. Both compounds decreased 10-30 folds in twenty years (Lunden \& Noren, 1998). It is noteworthy that the concentrations of DDT and its metabolites found in developing countries are normally higher than in industrialized countries. The maximum values of DDTs in human milk reported in 1990's are in Zimbabwe (Chikuni et al., 1997), where the total DDTs value ranged from 1607 to $25,259 \mathrm{ng} / \mathrm{g}$ milk fat. The total DDT residues in human milk in Beijing is lower than most of developing countries compared in Table 3 in the same period, and similar with that of Canada, Sweden and Japan. But it should be pointed out that most of the investigations listed in this report focused on rural individuals, while the mothers in this research are living in a modern city and have seldom chance to contact these compounds directly.

Ratio of $\mathbf{p}, \mathbf{p}^{\prime}$-DDE/p, $\mathbf{p}^{\prime}$-DDT in the human milk can be used as an indicator of past and present exposure to these dichlorodiphenylethane compounds. When 
the usage of $p, p^{\prime}$-DDT ceased, its residue in human milk decreased rapidly, however people may be exposed to its more persistent metabolite $p, p^{\prime}$-DDE continuously through foodstuff and the $\mathrm{p}, \mathrm{p}^{\prime}$-DDT in the body also convert to p, $\mathbf{p}^{\prime}$-DDE (Alawi et al., 1992). Thus the ratio of DDE/DDT in human milk will increase along with the stopping of use of DDT. As shown in Table 3, the DDE/DDT value in Jordan is only 0.44 , which suggested the mothers were continuously exposing to DDT contamination. The ratio between $p, p^{\prime}-D D E$ and p,p'-DDT mean values is 5.1 in present study; this ratio is comparable with data of India and Iran, but lower than other countries compared in Table 3, except Jordan. This result reflects that the production and consumption of $p, p^{\prime}-D D T$ is still existing in some Asian countries.

Table 3. Organochlorine compounds in milk in various countries (ng/g fat weight)

\begin{tabular}{lcccccccl}
\hline Countries & \multicolumn{1}{l}{ Number $\alpha-H C H$} & $\beta-H C H$ & $\gamma$-HCH & DDE & \multicolumn{1}{l}{ DDT } & DDE/DDT References \\
\hline Spain & 51 & 34 & 235 & 10 & 604 & 12 & 50 & Hemandez et al, 1993 \\
France & 20 & 52 & 287 & 37 & 2183 & 79 & 28 & Bordet et al, 1993 \\
Sweden & 40 & na $^{\text {a }}$ & na & Na & 227 & 22 & 10.3 & Lunden \& Noren, 1998 \\
Greece & 112 & 6.01 & 15.5 & 6.98 & 721.2 & 65.9 & 10.9 & Schinas et al, 2000 \\
Canada & 497 & 0.31 & 22.6 & 1.03 & 222 & 22.1 & 10.0 & Newsome et al, 1995 \\
Mexico & 60 & 10 & 60 & 10 & 4000 & 650 & 6.2 & Waliszewski et al, 2001 \\
Uganda & 143 & 100 & 70 & 440 & 2350 & 570 & 4.1 & Ejobi et al, 1996 \\
Nicaragua & 101 & nd & 6 & 1 & 2805 & 129 & 21.7 & Romero et al, 2000 \\
India & 25 & 432 & 5550 & 47 & 1265 & 250 & 5.1 & Tanabe et al, 1990 \\
Turkey & 104 & 58.5 & 386 & 16 & 2055 & 106.5 & 16 & Cok et al, 1997 \\
Jordan & 411 & 180 & na & 710 & 1410 & 4400 & 0.44 & Nasir et al, 1998 \\
Japan & 125 & na & 420 & Na & 330 & na & - & Najagawa et al, 1998 \\
Iran & 40 & 22 & 182 & 399 & 1701 & 302 & 5.6 & Cok et al, 1999 \\
Beijing & 45 & 63.9 & 49.5 & 55.6 & 422.3 & 83.5 & 5.1 & Present study \\
\hline
\end{tabular}

${ }^{\mathrm{a}}$ na= not analyzed; ${ }^{\mathrm{b}} \mathrm{nd}=$ not detectable

It is difficult to estimate accurately the amount of intake of each of these compounds by an infant, as it depends on the body burden of the mother, the percentage of milk fat, the quantity of milk intake and so on (Galetin-Smith et al., 1990). WHO has proposed as acceptable daily intake (ADI) for a breast-fed infant based on the average concentration of milk fat, as well as on infant weight and milk-consumption data. The ADI values for an infant with body weight of $5 \mathrm{~kg}$ who intakes $0.8 \mathrm{~kg}$ human milk per day, are $20 \mu \mathrm{g} / \mathrm{kg}$ body weight (b.w.) for total DDT compounds, $8 \mu \mathrm{g} / \mathrm{kg} \mathrm{b.w.} \mathrm{for} \gamma$-HCH (Jensen \& Slorach, 1991). According to our data, we assumed that, the inputs to an infant intakes $150 \mathrm{~g} / \mathrm{kg}$ body weight (with mean fat content $4 \%$ ), then the estimated daily intake (EDI) of infants living in Beijing are $1 \mu \mathrm{g} / \mathrm{kg}$ b.w. for total HCHs, and $4.3 \mu \mathrm{g} / \mathrm{kg}$ b.w. for total DDTs. None of mean levels of organochlorine compounds investigated in this study exceeded the WHO recommendations. 
Acknowledgements. This work was supported the Chinese Academy of Sciences (KZCX2-414) and the State High Tech Development Plan (2001AA646010)

\section{REFERENCES}

Alawi MA, Ammari N, Al-Shuraiki Y (1992) Organochlorine pesticide contaminations in human milk samples from women living in Amman, Jordan. Arch Environ Contam Toxicol 23: 235-239

Albers JMC, Kreis IA, Liem AKD, van Zoonen P (1996) Factors that influence the level of contamination of human milk with polychlorinated organic compounds. Arch Environ Contam Toxicol 30: 285-291

Bordet F, Mallet J, Maurice L, Borel S, Venant A (1993) Organochlorine pesticides and PCB congener content of French human milk. Bull Environ Contam Toxicol 50: 425-432

Chikuni O, Nhachi CF, Nyazema NZ, Polder A, Nafstad I, Skaare JU (1997) Assessment of environmental pollution by PCBs, DDT and its metabolites using human milk of mothers in Zimbabwe. Sci Total Environ 199: 183-190

Cok I, Bilgili A, Ozdemir M, Ozbek H, Bilgili N, Burgaz S (1997) Organochlorine pesticide residues in human breast milk from agricultural regions of Turkey, 1995-1996. Bull Environ Contam Toxicol 59: 577-582

Cok I, Karakaya AE, Afkham BL, Burgaz S (1999) Organochlorine pesticide contaminants in human milk samples collected in Tebriz (Iran). Bull Environ Contam Toxicol 63: 444-450

Czaja K, Ludwicki JK, Góralczyk K, Struciński P (2001) Relationship between two consecutive lactations and fat level in persistent organochlorine compound concentrations in human breast milk. Chemosphere 43: 889-893

Ejobi F, Kanja LW, Kyule MN, Muller P, Kruger J, Latigo AAR (1996) Organochlorine pesticide residues in mother's milk in Uganda. Bull Environ Contam Toxicol 56: 873-880

Galetin-Smith R, Pavkov S, Roncevic N (1990) DDT and PCBs in human milk: implication for breast feeding infants. Bull Environ Contain Toxicol 45: 811-818

Hemandez LM, Fernandez MA, Hoyas E, Gonzalez MJ, Garcia JF (1993) Organochlorine insecticide and polychlorinated biphenyl residues in human breast milk in Madrid. Bull Environ Contam Toxicol 50: 308-315

Iwata H, Tanabe S, Sakai N, Tatsukawa R (1993) Distribution of persistent organochlorines in the oceanic air and surface seawater and the role of ocean on their global transport and fate. Environ Sci Technol 27: 1080-1098

Jensen AA (1983) Chemical contaminants in human milk. Residue Rev 89: 1-128

Jensen AA, Slorach SA (1991) Chemical contaminants in human milk. CRC Press, Inc, Boca RatonFlorida, USA

Li YF (1999) Global technical hexachlorocyclohexane usage and its contamination consequences in the environment: from 1988 to 1997 . Sci Total Environ 232: 121-158 
Lunden A, Noren K (1998) Polychlorinated naphthalenes and other organochlorine contaminants in Swedish human milk, 1972-1992. Arch Environ Contam Toxicol 34: 414-423

Najagawa R, Hirakawa H, Iida T, Matsueda T, Nagayama J (1998) Maternal body burden of organochlorine pesticides and Dioxins. J AOAC Int 82: 716-724

Nasir K, Bilto YY, Al-shuraiki Y (1998) Residues of chlorinated hydrocarbon insecticides in human milk of Jordanian women. Environ Pollut 99: 141-148

Newsome WH, Davies D, Docet $J$ (1995) PCB and organochlorine pesticides in Canadian human milk-1992. Chemosphere 30: 2143-2153

Romero MLL, Dorea JG, Granja ACC (2000) Concentrations of organochlorine pesticides in Milk of Nicaraguan mothers. Arch Environ Health 55: 274-278

Schinas V, Leotsinidis M, Alexopoulos A, Tsapanos V, Kondakis XG (2000) Organochlorine pesticide residues in human breast from southwest Greece: Associations with weekly food consumption patterns of mothers. Arch Environ Health 55: 411-417

Tanabe S, Gondaira F, Subramanian A, Ramesh A, Mohan D, Kumaran P, Venugopalan VK, Tatsukawa R (1990) Specific pattern of persistent organochlorine residues in human breast milk from south India. J Agric Food Chem 38: 899-903

Waliszewski SM, Aguirre AA, Infanzon RM, Silva CS, Siliceo J (2001) Organochlorine pesticide levels in maternal adipose tissue, maternal blood serum, umbilical blood serum, and milk from inhabitants of Veracruz, Mexico. Arch Environ Contam Toxicol 40: 432-438 